\title{
Nutritional Status of the Patients with Chronic Liver Disease are More often Overlooked During Clinical Observations
}

\author{
Guney Merve ${ }^{1 *}$ and Basaranoglu Metin ${ }^{2}$ \\ ${ }^{1}$ Nutrition and Diet Department, Bezmialem Vakif University Medical Faculty Hospital, Turkey \\ ${ }^{2}$ Division of Gastroenterology, Bezmialem Vakif University Faculty of Medicine, Turkey
}

Submission: May 19, 2020; Published: July 02, 2020

*Corresponding author: Merve Guney, Nutrition and Diet Department, Bezmialem Vakif University Medical Faculty Hospital, Silahtarağa Caddesi No:198 Alibeyköy/Eyüp, İSTANBUL, Turkey

\begin{abstract}
Background: Chronic liver diseases are one of the major cause of mortality and morbidity in the world. Life style modifications such as diet and physical activity status of the patients are more often overlooked during clinical observations despite the benefits on patients with chronic liver disease. The aim of present study is to assess the nutritional status of patients with chronic liver disease at out-patient clinical setting. We examined whether patients are make any modification on their diet for their chronic liver disease. If yes, are those modifications professional or unprofessional. Use of specific plants and junk foods consumption were specifically evaluated. Physical activity status were determined, too.

Methods and Material: Patients with any chronic liver diseases that we follow in our Hepatology out-patient clinic were included in this study. We used a basic questionnaire. We evaluated anthropometric measurements of 38 patients with chronic liver disease due to any hepatic etiology.

Results: Half of the patients were obese $(n=19)$. Of the 38 patients, $9(24 \%)$ followed special diet and $78 \%$ of them were prescribed diet program by doctor who are not qualified in nutrition. Only $18 \%(n=7)$ do regular physical activity 150 mins/week.

Conclusion: We most importantly found that all of the participants of the current study were obese or overweight (84\%) and physically inactive (82\%). And most of the participants didn't consult the specialist about diet or any life style intervention. It is well known that weight loss by both Mediterranean diet and increased physical activity could improve hepatic abnormalities such as necroinflammation and hepatic steatosis in patients with chronic liver disease due to any cause. Lifestyle modifications such as diet and physical activity status of the patients are more often overlooked during clinical observations and nutritional consultation is now a necessary issue for the gastroenterology and hepatology out-patient clinics.

Keywords: Nutritional status; Chronic liver disease; Physical activity; Gastroenterology and hepatology; Medicinal plants

Abbreviations: NAFLD: Non-Alcoholic Fatty Liver Disease; NASH: Non-Alcoholic Steatohepatitis; BMI: Body Mass Index; WHO: World Health Organization
\end{abstract}

\section{Introduction}

Current and historical prevalence and mortality data from published sources and international databases show that liver disease is a very important and growing public health problem in European countries [1]. In some parts of Europe, it is estimated that there are more than 1100/10000 cirrhosis and other chronic liver patients. Chronic liver diseases are one of the major cause of mortality and morbidity in the World. Prevalence of chronic liver disease are increasing with behavioral issues such as alcohol consumption and obesity. According to the HEPAHEALTH project carried out by EASL; Behavioral barriers to liver health include alcohol consumption, obesity, diabetes and metabolic syndrome. Lifestyle modifications such as diet and physical activity status of the patients are more often overlooked during clinical observations despite the benefits on patients with chronic liver disease $[2,3]$.

Different foods consumed in our daily diet may be beneficial or harmful to the liver. Certain selected vegetables, fruits, medicinal plants can provide nutritional and medical support for chronic liver diseases [4]. On the other hand, fast-food consumption are known as the cause of some liver diseases and some abnormalities in the liver (such non-alcoholic fatty liver disease (NAFLD) and 
non-alcoholic steatohepatitis (NASH)) [5]. High-fat diet cause obesity, insulin resistance, and hepatic steatosis. This diet leads to increased hepatic fibrosis, inflammation, endoplasmic reticulum stress and lipoapoptosis gene expression. In chronic liver diseases with complex pathogenesis, it is important to evaluate the body weight, diet and physical activity status. Furthermore, specific approaches are needed.

The aim of present study is to assess the nutritional status of patients with chronic liver disease due to any cause. We examined whether patients are make any modification on their diet for their chronic liver disease and if yes, are those modifications professional or unprofessional. Moreover, determination of the use of specific plants which is known as beneficial for the liver health and junk foods consumption which is known as harmful to the liver health were done. Additionally, physical activity status were questioned. Recommendations regarding needs for future research were studied.

\section{Patients, Materials and Methods}

Outpatients with chronic liver diseases that we follow in our Gastroenterology and Hepatology clinic were included in this study. Patients with cirrhosis were excluded due to their different metabolic, nutritional and psychologic behavior. In the present study, a basic questionnaire was used and we evaluated anthropometric measurements of 38 patients. Body Mass Index (BMI) values were calculated according to self-reported body weight $(\mathrm{kg}) /$ height $\left(\mathrm{m}^{2}\right)$ [6]. World Health Organization (WHO) classification was used to group the patients into 6 categories: underweight (BMI $<18.5 \mathrm{~kg} / \mathrm{m}^{2}$ ), normal weight (BMI between 18.5 and $24.9 \mathrm{~kg} / \mathrm{m}^{2}$ ), overweight (BMI between 25.0 and 29.9 $\left.\mathrm{kg} / \mathrm{m}^{2}\right)$, and obese class I ( $\left.30-34.99 \mathrm{~kg} / \mathrm{m}^{2}\right)$, obese class II (35$\left.39.99 \mathrm{~kg} / \mathrm{m}^{2}\right)$, obese class III $\left(\mathrm{BM} \geq 40 \mathrm{~kg} / \mathrm{m}^{2}\right)$.

Self-reported socio-demographic data included age, gender, marital status, education, employment status, and living situation (villages, town, city, and metropolitan). Methods of nutritional assessment that required the patient to be hospitalized or that involved invasive techniques and could be unpleasant and cause poor patient compliance were purposely avoided. Weight changes during the last six months was asked to determine the nutritional status of the patients. Patients were asked whether they had a special diet program for chronic liver disease, and if any, who was recommended the diet. Smoking and alcohol use were questioned. The current scientific evidence was reviewed in order to determine certain foods that could be good and bad for liver health and the frequency and amount of consumption of this foods were questioned by the researchers. Lemon, artichoke, cabbage, radish, onion, green tea, red apple, cauliflower, garlic, honey, pollen, walnut, turmeric, spinach, banana, broccoli, grapefruit and avocado were among the good foods for liver health in the survey. Margarine, pastries, pastry, sherbet desserts, milky desserts, fast food, doner kebab, chips, chocolate, biscuits, fizzy drinks, fruit juices are among the foods that may adversely affect the existing chronic liver disease. As a result, how much and how often these foods were consumed by patients were asked. Finally, physical activity status of the patients were determined.

Data were analyzed with the Statistical Package for the Social Sciences (SPSS) version 16.0. Descriptive statistics were performed to categorize and calculate the distribution and frequency of variables. Numerical variables were presented as means with SDs and median with minimum and maximum values. The distribution of the data was examined by Shapiro Wilk test. Categorical changes are indicated as $\mathrm{n}(\%)$. This study was conducted according to the guidelines laid down in the Declaration of Helsinki and all procedures involving human subjects/participants were approved by the Bezmialem Vakif University Ethical Committee for Clinical Researches (No: 54022451-050.05.04-) Written informed consent was obtained from all subjects/participants.

\section{Results}

Table 1: Patient characteristics.

\begin{tabular}{|c|c|c|}
\hline Participant Characteristics & $\mathbf{n}$ & $\%$ \\
\hline $\mathrm{N}$ & 38 & \\
\hline Age mean (SD) & $50.9(12,2)$ & \\
\hline \multicolumn{3}{|l|}{ Gender } \\
\hline Male & 15 & 39 \\
\hline Female & 23 & 61 \\
\hline \multicolumn{3}{|l|}{ Marital Status } \\
\hline Married & 33 & 87 \\
\hline Single & 5 & 13 \\
\hline \multicolumn{3}{|l|}{ Occupation } \\
\hline Unemployed & 1 & 3 \\
\hline Retired & 12 & 32 \\
\hline Housewife & 16 & 42 \\
\hline Employee & 9 & 24 \\
\hline \multicolumn{3}{|l|}{ Education } \\
\hline Basic Education & 22 & 58 \\
\hline High School & 12 & 32 \\
\hline University degree & 4 & 11 \\
\hline \multicolumn{3}{|l|}{ Living Status } \\
\hline Villages & 1 & 3 \\
\hline City & 1 & 3 \\
\hline Metropolitan & 36 & 95 \\
\hline \multicolumn{3}{|l|}{ Chronic Liver Disease Diagnoses } \\
\hline Hepatitis B & 20 & 53 \\
\hline NAFLD & 16 & 42 \\
\hline Autoimmune Hepatitis & 1 & 3 \\
\hline Primary Biliary Cirrhosis & 3 & 8 \\
\hline Cirrhosis & 1 & 3 \\
\hline Hepatitis C & 1 & 3 \\
\hline Wilson Disease & 1 & 3 \\
\hline
\end{tabular}


Thirty eight patients who were followed in Bezmialem Vakif University Hospital, Gastroenterology \& Hepatology Clinic with the diagnosis of chronic liver due to any cause were interviewed by face-to-face interview technique. Characteristics of the patients are given in Table 1 . There were 15 male and 23 female patients in the study between $22-74$ ages. Fifty-eight percent $(n=22)$ received primary education. The percentage of patients living in the metropolitan area was 95\% $(n=36)$. The diagnoses of the patients were Hepatitis B, NAFLD, Primary Biliary Cirrhosis, NASH, Autoimmune Hepatitis, Hepatitis C, and Wilson's Disease. Some patients had more than one diagnosis of chronic liver disease. The most common chronic liver disease in our outpatient clinic was Hepatitis B with 53\% ( $n=20)$, then, NAFLD with $42 \%$ $(n=16)$.

The mean BMI was $29.5 \mathrm{~kg} / \mathrm{m} 2$ which is defined as overweight by the WHO (Table 2) [6]. Half of the patients were obese $(n=19)$.
Twenty nine percent of the patients gain weight on an average of $4.5 \mathrm{~kg}$ and $24 \%$ of the patients lose weight on an average of 5.3 $\mathrm{kg}$ during the last 6 months. Only nine patients (24\%) followed special diet and $78 \%$ of them were prescribed diet program by doctor. Patients who used to smoke and drink were $8 \%$ and $1 \%$ respectively. Only four patients were current smoker and 1 patients were current drinker. In vitro and in vivo studies considered and reviewed by researchers. Lemon, artichoke, cabbage, green tea, apple, walnut, turmeric, banana, broccoli, avocado was determined as medicinal plants that beneficial for liver health [7-12]. Lemon was the most frequent vegetable and $79 \%$ of the patients consume lemon at least once a week. Avocado, broccoli, turmeric, green tea and artichoke wasn't consumed by most patients $89 \%, 58 \%, 71 \%, 79 \%$, and $61 \%$ respectively (Figure 1).

Table 2: Anthropometric measurements and nutritional status of the patients.

\begin{tabular}{|c|c|c|}
\hline & $\mathbf{n}$ & $\%$ \\
\hline Height $(\mathrm{cm})$ mean (SD) & $165(0,1)$ & \\
\hline Weight $(\mathrm{kg})$ mean (SD) & $80(12,4)$ & \\
\hline \multicolumn{3}{|l|}{ BMI $\left(\mathrm{kg} / \mathrm{m}^{2}\right)$} \\
\hline Normal BMI $18.5-24.9 \mathrm{~kg} / \mathrm{m}^{2}$ & 6 & 16 \\
\hline Overweight BMI $25-29.9 \mathrm{~kg} / \mathrm{m}^{2}$ & 13 & 34 \\
\hline Obesity BMI $>30 \mathrm{~kg} / \mathrm{m}^{2}$ & 19 & 50 \\
\hline Weight loss during the last 6 months $n$ (average) & $9(5,3)$ & 24 \\
\hline Weight gain during the last 6 months $n$ (average) & $11(4,5)$ & 29 \\
\hline \multicolumn{3}{|l|}{ Following special diet program } \\
\hline Yes & 9 & 24 \\
\hline No & 29 & 76 \\
\hline \multicolumn{3}{|l|}{ Who prescribes the diet program } \\
\hline Doctor & 7 & 78 \\
\hline Dietitian & 3 & 33 \\
\hline Others & 1 & 11 \\
\hline \multicolumn{3}{|l|}{ Smoking } \\
\hline No & 26 & 68 \\
\hline Used to smoke & 8 & 21 \\
\hline Yes & 4 & 11 \\
\hline \multicolumn{3}{|l|}{ Alcohol } \\
\hline No & 30 & 79 \\
\hline Used to smoke & 7 & 18 \\
\hline Yes & 1 & 3 \\
\hline
\end{tabular}

Fast-food, chocolates, biscuits, chips, fizzy drinks, and fruit juice were determined as unhealthy. These foods are more likely to have high fructose corn syrup in them and known as harmful for liver health [5]. In our study population fruit juice, fizzy drink, chips and fast-food were not consume by the most patients $76 \%$, $74 \%, 84 \%$, and $79 \%$ respectively (Figure 2). Only 18\% $(n=7)$ of the patients do regular physical activity more than 150 mins/ week (Figure 3). 


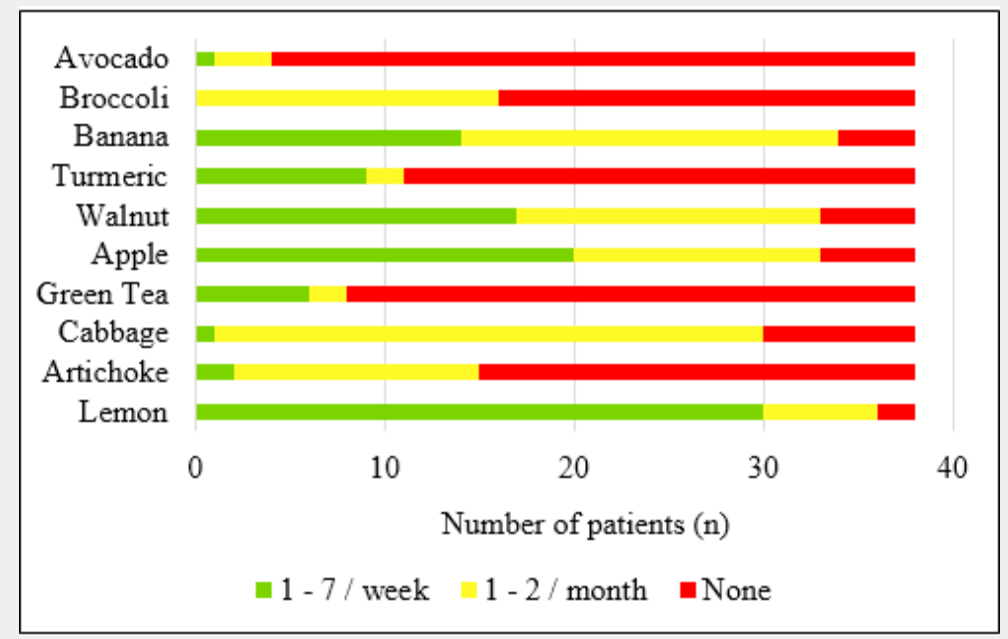

Figure 1: Medicinal plants consumption frequency by patients.

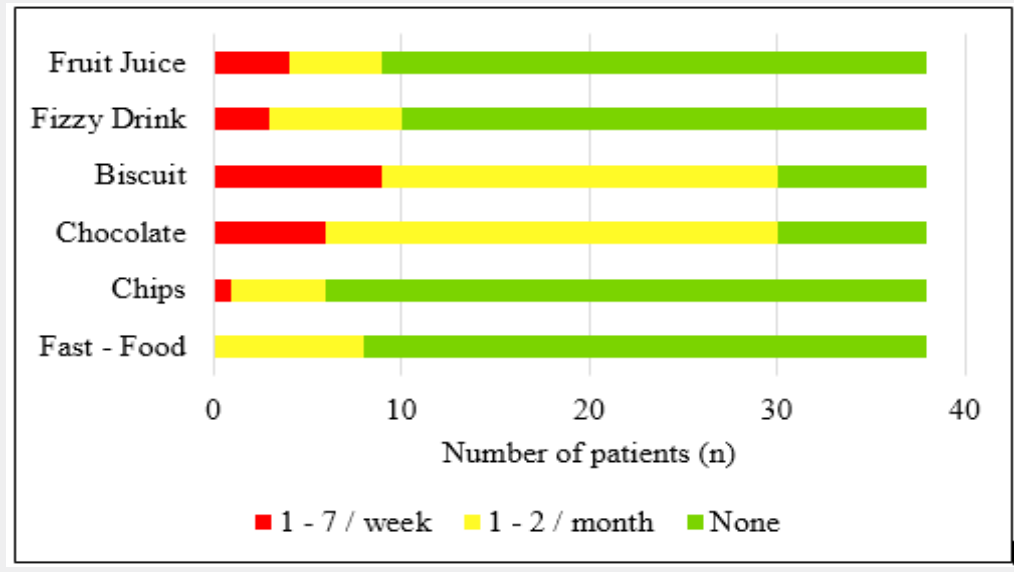

Figure 2: Unhealthy foods and drinks consumption by patients.

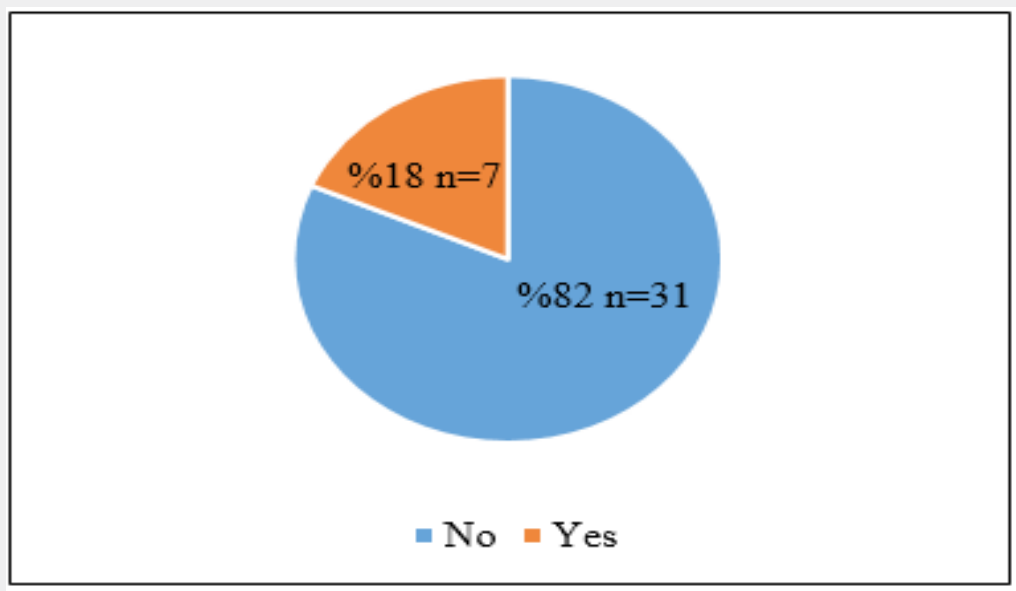

Figure 3: Physical activity status of patients. 


\section{Discussion}

Obesity and overweight prevalence was $60 \%$ in general Turkish population [13]. In fact, in this study almost all of our patients with chronic liver disease were obese or overweight. This results suggest that patient with chronic liver disease do need special approaches for their eating behavior [14,15]. Although, it is known that weight loss generally reduces hepatic steatosis, achieved either by hypocaloric diet alone or in conjunction with increased physical activity [16]. Furthermore, loss of at least $3-5 \%$ of body weight appears necessary to improve steatosis, but a greater weight loss (up to $10 \%$ ) may be needed to improve necroinflammation. As results, such life style interventions are important component of the management of those with chronic liver disease. In contrast to these findings, participants of the current study were obese or overweight $(84 \%)$ and physically inactive (82\%). And most of the participants didn't consult the specialist about diet or any life style intervention. Most of the patients (78\%) in our study got dietary advice from doctors who are not qualified in nutrition. Only a few participants had the purpose of losing weight in order to improve health status.

A few studies have also demonstrated that weight loss and physical activity interventions may help to improve in liver histology, reduction in steatosis, fibrosis, and abnormal liver enzymes in patients with chronic liver disease even in patients with hepatitis C [17-19]. Results of the medicinal plants habits match with Turkish eating patterns as it is shown in Figure 1. We observed that patients were well aware and educated about unhealthy foods and drinks such as fast foods, chips, fizzy drinks and fruit juices. Most of them known the bad effects of them to their liver health. Unfortunately, patients were consumed biscuits and chocolates and they were uneducated about these kind of packaged foods and their effects on their liver health. According to practice guideline by the American Association for the Study of Liver Diseases, American College of Gastroenterology, and the American Gastroenterological Association no information exists on recommending any particular type of diet or exercise. Further studies are needed to assess the efficacy of specific diets. Finally, it is important to determine the short and long-term effects of any intervention for liver health.

\section{References}

1. Pimpin L, Cortez-Pinto H, Negro F, Corbould E, Lazarus JV, et. Al. (2018) EASL HEPAHEALTH Steering Committee. Burden of liver disease in Europe: epidemiology and analysis of risk factors to identify prevention policies. Journal of hepatology 69(3): 718-735.

2. European Association for the Study of the Liver, \& European Association for the Study of Diabetes (2016) EASL-EASD-EASO Clinical Practice Guidelines for the management of non-alcoholic fatty liver disease. Obesity facts $9(2): 65-90$.

3. Osland EJ, Powell EE, Banks M, Jonsson JR, Hickman IJ (2007) Obesity management in liver clinics: translation of research into clinical practice. J Gastroenterol hepatol 22(4): 504-509.

4. Jin X, Zheng RH, Li YM (2008) Green tea consumption and liver disease: a systematic review. Liver international 28(7): 990-996.

5. Basaranoglu M, Basaranoglu G, Sabuncu T, Sentürk H (2013) Fructose as a key player in the development of fatty liver disease. World J Gastroenterol 19(8): 1166-1172.

6. WHO (2008) Body Mass Index Waist Circumference and Waist-Hip Ratio Report of a WHO Expert Consultation.

7. Kobayashi H, Tanaka Y, Asagiri K, Asakawa T, Tanikawa K, et. al. (2010) The antioxidant effect of green tea catechin ameliorates experimental liver injury. Phytomedicine 17(3-4): 197-202.

8. Neveen M El-Sherif, Noha M Issa (2017) The Possible Anti-fibrotic Effect of Artichoke on the Liver and Heart of Bile Duct Ligation Rat Model. Anatomy Physiology \& Biochemistry International Journal 2(1): 555577.

9. Yang X, Yang S, Guo Y, Jiao Y, Zhao Y (2013) Compositional characterisation of soluble apple polysaccharides, and their antioxidant and hepatoprotective effects on acute CCl4-caused liver damage in mice. Food Chemistry 138(2-3): 1256-1264.

10. Shimoda H, Tanaka J, Kikuchi M, Fukuda T, Ito H, et al. (2008) Walnut polyphenols prevent liver damage induced by carbon tetrachloride and d-galactosamine: hepatoprotective hydrolyzable tannins in the kernel pellicles of walnut. J agric food chem 56(12): 4444-4449.

11. Bruck R, Ashkenazi M, Weiss S, Goldiner I, Shapiro H, et al. (2007) Prevention of liver cirrhosis in rats by curcumin. Liver International 27(3): 373-383.

12. Shu JC, He YJ, Lv X, Ye GR (2009) Curcumin prevents liver fibrosis by inducing apoptosis and suppressing activation of hepatic stellate cells. J nat med 63(4): 415-420.

13. Sağlık Araștırmaları Genel Müdürlügü, Sağlık Bakanlığ (2010) "Türkiye Beslenme ve Sağlık Araştırması.

14. Basaranoglu M, Basaranoglu G (2011) Pathophysiology of insulin resistance and steatosis in patients with chronic viral hepatitis. World J Gastroenterol 17(36): 4055-4062.

15. Tetri LH, Basaranoglu M, Brunt EM, Yerian LM, Neuschwander-Tetri BA (2008) Severe NAFLD with hepatic necroinflammatory changes in mice fed trans fats and a high-fructose corn syrup equivalent. Am J Physiol Gastrointest Liver Physiol 295(5): G987-1095.

16. Chalasani N, Younossi Z, Lavine JE, Diehl AM, Brunt EM, et al. (2012) The diagnosis and management of non-alcoholic fatty liver disease: Practice Guideline by the American Association for the Study of Liver Diseases, American College of Gastroenterology, and the American Gastroenterological Association. Hepatology 55(6): 2005-2023.

17. Hickman IJ, Jonsson JR, Prins JB, Ash S, Purdie DM, et al. (2004) Modest weight loss and physical activity in overweight patients with chronic liver disease results in sustained improvements in alanine aminotransferase, fasting insulin, and quality of life. Gut 53(3): 413419.

18. Hickman IJ, Clouston AD, Macdonald GA, Purdie DM, Prins JB, et al. (2002) Effect of weight reduction on liver histology and biochemistry in patients with chronic hepatitis C. Gut 51(1): 89-94.

19. St. George A, Bauman A, Johnston A, Farrell G, Chey T, et al. (2009) Effect of a lifestyle intervention in patients with abnormal liver enzymes and metabolic risk factors. J gastroenterol hepatol 24(3): 399-407. 
This work is licensed under Creative Commons Attribution 4.0 License DOI:10.19080/ARGH.2020.15.555912
Your next submission with JuniperPublishers will reach you the below assets

- Quality Editorial service

- Swift Peer Review

- Reprints availability

- E-prints Service

- Manuscript Podcast for convenient understanding

- Global attainment for your research

- Manuscript accessibility in different formats ( Pdf, E-pub, Full Text, audio)

- Unceasing customer service

Track the below URL for one-step submission https://juniperpublishers.com/online-submission.php 